\title{
The influence of heat treatment on the quality of screen printed textile substrates
}

\author{
Nemanja Kašiković ${ }^{1}$, Mladen Stančić ${ }^{2}$,Gojko Vladić ${ }^{1}$, Dragana Grujić ${ }^{3}$ \\ Dragoljub Novaković ${ }^{1}$, Rastko Milošević ${ }^{1}$, Ivan Pinćjer ${ }^{1}$
}

\footnotetext{
${ }^{1}$ University of Novi Sad, Faculty of Technical Sciences, Department of Graphic Engineering and Design, Novi Sad, Serbia e-mail: rastko.m@uns.ac.rs

${ }^{2}$ University of Banja Luka, Faculty of Technology, Department of Graphic Engineering, Banja Luka, Bosnia and Herzegovina

${ }^{3}$ University of Banja Luka, Faculty of Technology, Department of Textile Engineering, Banja Luka, Bosnia and Herzegovina

e-mail: knemanja@uns.ac.rs,mladen.stancic@unibl.rs, vladicg@uns.ac.rs, dragana.grujic@tfbl.org, novakd@uns.ac.rs, pintier@uns.ac.rs
}

\begin{abstract}
During exploitation, textile products printed with screen printing technique are quite often exposed to various influences, one of which is a heat treatment- firstly during the production process and later on when ironing. Heat is simultaneously affecting deposited colorants (ink) on the surface of the substrate material, as well as textile fibers in the material structure. As a result, colorimetric characteristics of printed colorants are changed. The research presented in this paper aims to determine the influence of heat treatment on color changes of screen printed textile substrates, observed in CIE L*, $a^{*}, b^{*}$ color space. Macro non-uniformity of the printed cotton textile materials was analyzed as a function of temperature levels applied during thermal treatments and textile material characteristics, as well as mesh counts of screens used in the printing process. The results show that thermal treatment affects the color change of printed samples.
\end{abstract}

Keywords: cotton, screen printing, heat treatment, print quality, macro non-uniformity

\section{INTRODUCTION}

Textile printing is a crucial and versatile method for introducing color and design to textile fabrics [1]. The most important printing technique in textile printing is the screen printing technique [2,3], which is characterised by low costs and high productivity in the case of high production volume. Amongst various textile materials, cotton is the most frequently used printing substrate [4] and it is known to possess good thermal properties [5-7].

After the printing process, prints are subjected to various influences like sunlight, chemical agents, heat, washing treatments etc., which lead to changes and deterioration of the print quality [8-11]. Heat treatment affects the quality of the finished printed textile products and is applied using a variety of techniques. Heat can be transferred by conduction, radiation and convection [12-14] and influences both the textile fibers of the substrate material and the printed ink. This leads to print quality changes, especially of the printed ink color (K/S values, gloss, CIE Lab coordinates). In order to quantify these color changes caused by heat treatment, spectrophotometric measurements were used in addition to the standard visual gray scale method. If the goals are to achieve high-quality prints and standardized color reproduction, visual judgment as a print quality control method is not sufficient. Therefore, color measurement devices like spectrophotometers and colorimeters are frequently used for color characterization. Although spectrophotometers give the most accurate estimations, they are often replaced by colorimeters because of their affordability.

In order to determine color differences $\Delta \mathrm{E}$ is calculated. The perceptual interpretation of the color difference $\Delta \mathrm{E}$ is not clear; roughly said, a noticeable difference is about $1 \Delta \mathrm{E}, \Delta \mathrm{E}<3$ hardly perceptible, $3<$ $\Delta \mathrm{E}<6$ perceptible but acceptable, as well as $\Delta \mathrm{E}>6$ unacceptable [15]. Although the color of the prints is an important parameter, color difference determination is not a sufficient method to determine the overall print quality, as the print quality is not a monotonic function of color parameters [16-19]. Attributes such as 
contrast, sharpness, image noise, micro and macro non-uniformity, and gloss uniformity are not directly tied to color reproduction but they are still very important in terms of overall print quality [19-21]. These parameters are directly related to dot and line reproduction, which are integral parts of the most printed products. Still, there is no consensus amongst researchers which parameter is the most important [22]. Some researchers claim that macro non-uniformity, color range, sharpness and color differences are the most important ones [23]. Macro non-uniformity (print mottle) is often a shortcoming of printed images and it represents unwanted irregularities in the perceived optical density of the print. It can be caused by an uneven absorption of ink by the printing substrate, resulting in fuzzy and "cloudy" areas on the printed surface [22, 24]. It is not possible to perceive more than five quality attributes at the same time [23, 25].

This paper aims to determine the influence of heat treatment on the print quality, i.e. color reproduction and macro non-uniformity. Variable parameters were used, including different screen mesh counts for printing processes, textile substrates with different properties and varying temperature levels for heat treatments.

\section{MATERIALS AND METHODS}

This section should describe all the materials, procedures and methods used in the experimental or theoretical part of the work. Three different cotton textile materials were used in this experiment. Material characterization was conducted by a contracted laboratory (ProfiLAB, Serbia) according to the following standards: material composition (ISO 1833), fabric weight (ISO 3801) and thread count (ISO 7211-2). The properties are presented in Table 1. The rest of the tests have performed the authors at the University of Novi Sad, Serbia, Faculty of Technical Sciences, Department of Graphic Engineering and Design.

Using the Adobe Illustrator software (CS5, USA), a custom test target was created, containing several elements for print quality evaluation. The influence of heat treatment was analyzed on the patches printed with 100\% cyan ink (Texopaque Classic OP Trich Cyan, FUJIFILM Sericol, Japan) sized 30 x $120 \mathrm{~mm}$.

Analyzed samples were printed using the screen printing machine M\&R Sportsman (E Series, USA). For the printing process, four screen meshes $(500 \times 760 \mathrm{~mm})$ with four different mesh counts $(90,120,140$ and 160 threads/cm) were used (Ševa-Grafika, Serbia), which were fixed on aluminum frames $(580 \times 840$ $\mathrm{mm}$ ) (Ševa-Grafika, Serbia).

Table 1: Characteristics of material used in testing.

\begin{tabular}{l|l|l|l|l}
\hline \multirow{2}{*}{ TESTS } & \multirow{2}{*}{ MATERIAL COMPOSITION (\%) } & \multirow{2}{*}{ FABRIC WEIGHT (G/M $\left.{ }^{2}\right)$} & \multicolumn{2}{|l}{ THREAD COUNT $\left(\mathbf{C M}^{-1}\right)$} \\
\cline { 3 - 5 } & & & WARP & WEFT \\
\hline Method & ISO 1833 & ISO 3801 & \multicolumn{2}{|l}{ ISO 7211-2 } \\
\hline Material A & Cotton $100 \%$ & 138 & 14 & 19 \\
\hline Material B & Cotton $100 \%$ & 185 & 15 & 16 \\
\hline Material C & Cotton $100 \%$ & 207 & 12 & 18 \\
\hline
\end{tabular}

The development of the printing master was done using the conventional method with linearized positive film. For transparent film areas, the optical density was 0.03 and for opaque areas, it was 4.1. The liniature of the film was 5 times smaller than the mesh count of the printing screen. Sericol Dirasol 915 (Supercoat, FUJIFILM Sericol, Japan) photosensitive emulsion was then used. Exposure was conducted using Metal halide Vacuum Exposure Unit (Ranar, USA). The Autotype Exposure Calculator (Dirasol, FUJIFILM Sericol, Japan) was used to determine exposure time for the printing master. Printing parameters and heat treatment conditions are presented in Figure 1.

Investigation of print quality includes color reproduction and macro non-uniformity analysis of the prints. The color reproduction of samples was analyzed by measuring the CIE Lab coordinates full tones cyan $(100 \%)$ as well as spectral curves before and after the thermal effects on the printed patterns.

Color differences were calculated based on the color measurements using the $\Delta \mathrm{E}_{2000}$ color difference formula. Using a spectrophotometer (HP200, Hanpu, China), CIE Lab colour coordinates were measured (illuminant $\mathrm{D} 65,10^{\circ}$ standard observer, measurement geometry $\mathrm{d} / 8$, aperture $8 \mathrm{~mm}$, without UV component). Spectral curves were captured using a spectro-densitometer (SpectroDens, Techkon, Germany) measuring device (illuminant D50, $2^{\circ}$ standard observer, measuring geometry $0^{\circ} / 45^{\circ}$, aperture $3 \mathrm{~mm}$ ). All measurements were repeated 10 times, after which the mean value was calculated. Macro non-uniformity was 
determined on the printed field of $100 \%$ cyan, size 25.4 x $25.4 \mathrm{~mm}$, using software for digital image processing (ImageJ, USA) [26]. Printed samples were scanned at the resolution of 600 spi using a CanoScan 5600F scanner (Canon, Japan), without automatic correction functions. Materials were placed on a matte, opaque white backing according to the ISO 13655 standard. Images used in the analysis were saved as TIFF files without compressions. SEM microscopic analysis, according to the procedure (gold coating to ensure conductivity), was used to both gain insight into the fiber structure [27] and the changes of the substrate surface caused by the printing process and the heat treatment. For this purpose, SEM electronic microscope (JSM 646 OLV, JEOL, Japan) was used. Samples were classified, marked and prepared for SEM analysis.

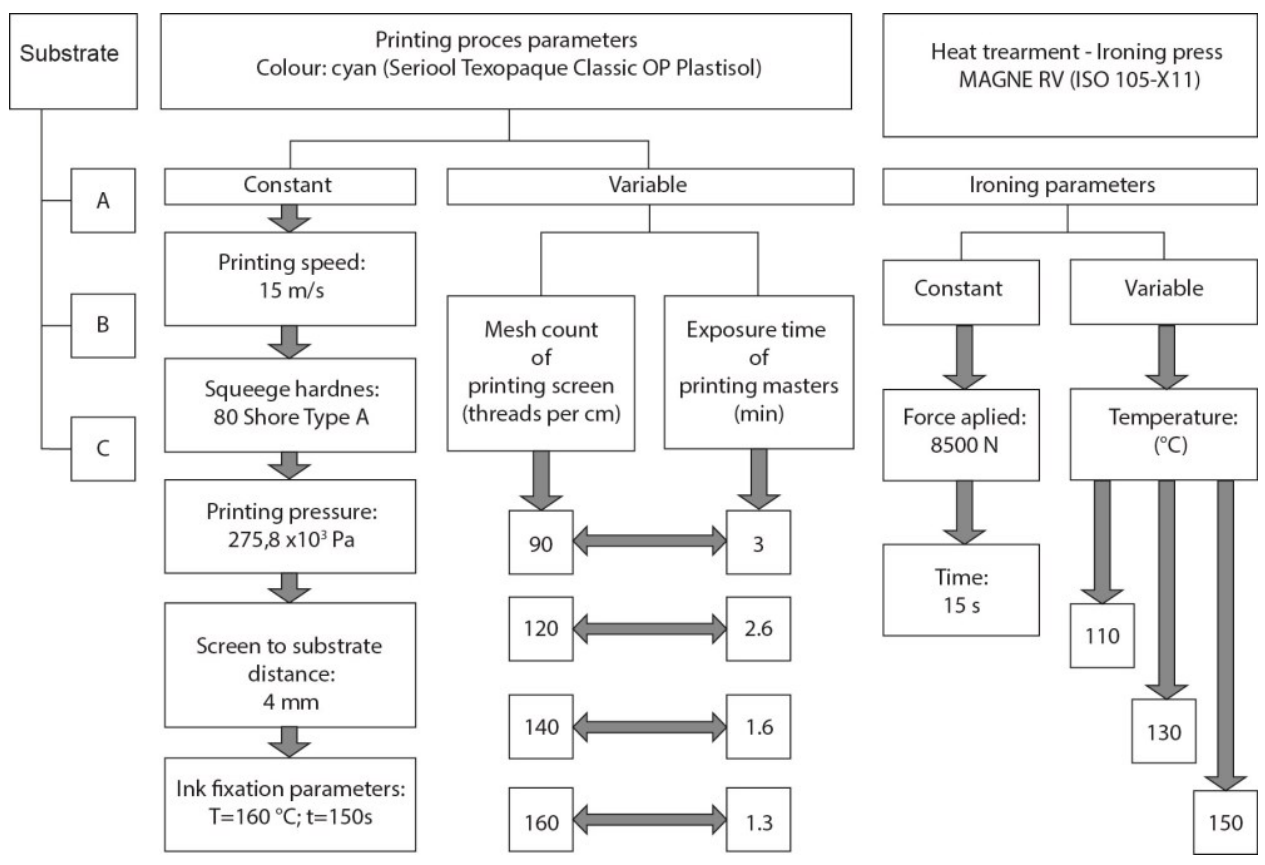

Figure 1: Printing parameters and heat treatment conditions.

\section{RESULTS AND DISCUSSION}

Quantified changes of the print characteristics caused by heat treatments are presented in separate sections for each considered print quality parameter.

\subsection{Spectrophotometric analysis of the samples before and after heat treatment}

According to spectrophotometric measurements of printed samples (CIE L, a, b colour coordinates) colour differences, $\Delta \mathrm{E}$ were calculated between the samples before and after heat treatment and presented in Table 2. The results show that the lowest lightness of the prints corresponds to the lowest screen mesh count. This can be explained by the fact that screens of lower density let through higher amounts of ink.

The analysis of the colour changes measured between samples before and after heat treatment shows that the greatest changes were caused by the highest temperature. The highest colour differences $(\Delta \mathrm{E})$ were caused by a temperature of $150{ }^{\circ} \mathrm{C}$, which generated values in colour difference from 2.3 to 3.2. Obtained colour difference values are hardly perceptible $(\Delta \mathrm{E}<3$, and some are perceptible but acceptable $(3<\Delta \mathrm{E}<6)$. A temperature of $110^{\circ} \mathrm{C}$ caused small colour differences, $\Delta \mathrm{E}(0.7-1)$ - keeping in mind that ink fixation is usually done at $160{ }^{\circ} \mathrm{C}$.

In the case of exposure to thermal treatments of $130{ }^{\circ} \mathrm{C}$, almost all calculated colour difference values, $\Delta \mathrm{E}$, were in the range of $1-2$, which is hardly a perceptible colour difference to the human visual system. Only samples of material C, printed using screen mesh count of 90 thread/cm, showed colour difference higher than 2 at $130{ }^{\circ} \mathrm{C}$.

When comparing samples printed on different materials under the same printing conditions exposed to the same thermal load level, the greatest colour differences were recorded for material $\mathrm{C}$, which has the highest fabric weight and the most pronounced surface roughness. The smallest colour differences before and after thermal treatment were calculated for materials with the lowest fabric weight (single weave). 
KASIKOVIC, N.;STANCIC, M.; VLADIC, G.; GRUJIC, D.; NOVAKOVIC, D.; MILOSEVIC, R.;.PINCJER, I. revista Matéria, v. 22,

n. $1,2017$.

Table 2: Colour differences after printing and thermal treatments of the samples.

\begin{tabular}{l|l|l|l}
\hline SAMPLE & $\begin{array}{l}\Delta \text { E VALUE FOR } \\
\text { MATERIAL A }\end{array}$ & $\begin{array}{l}\Delta \text { E VALUE FOR } \\
\text { MATERIAL B }\end{array}$ & $\begin{array}{l}\Delta \text { E VALUE FOR } \\
\text { MATERIAL C }\end{array}$ \\
\hline $90-P$ & - & - & - \\
\hline $90-110$ & 0.784128 & 0.817907 & 0.981417 \\
\hline $90-130$ & 1.833799 & 1.907594 & 2.08987 \\
\hline $90-150$ & 2.8562 & 3.0558 & 3.221036 \\
\hline $120-P$ & - & - & - \\
\hline $120-110$ & 0.764026 & 0.767429 & 0.923948 \\
\hline $120-130$ & 1.600782 & 1.668511 & 1.973833 \\
\hline $120-150$ & 2.703501 & 2.893979 & 3.083902 \\
\hline $140-P$ & - & - & - \\
\hline $140-110$ & 0.707033 & 0.759547 & 0.904834 \\
\hline $140-130$ & 1.375026 & 1.555923 & 1.882722 \\
\hline $140-150$ & 2.504565 & 2.810615 & 3.053656 \\
\hline $160-P$ & - & - & - \\
\hline $160-110$ & 0.675384 & 0.685665 & 0.762619 \\
\hline $160-130$ & 1.336431 & 1.419828 & 1.698444 \\
\hline $160-150$ & 2.274135 & 2.361838 & 2.909556 \\
\hline $\begin{array}{l}\text { Note: the first number represents screen mesh count; P is the mark of printed sam- } \\
\text { ple; } 110,130 \text { and } 150 \text { are values of thermal load in Celsius degrees. }\end{array}$ \\
\hline
\end{tabular}

\subsection{Analysis of heat treatment influence on spectral curves}

Spectral curves were registered before and after subjecting the samples to the heat treatment, using a Techkon SpectroDens measuring device. Figure 2 shows spectral curves for material A.

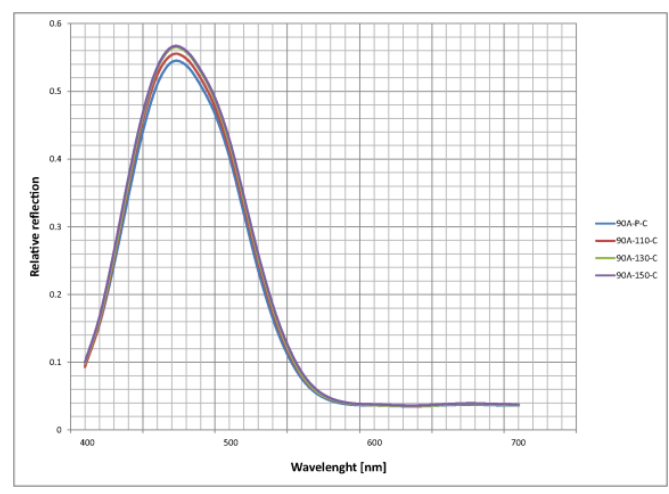

a)

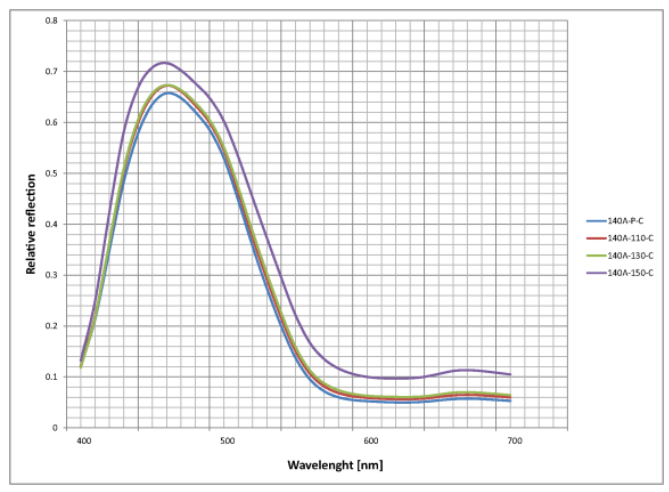

c)

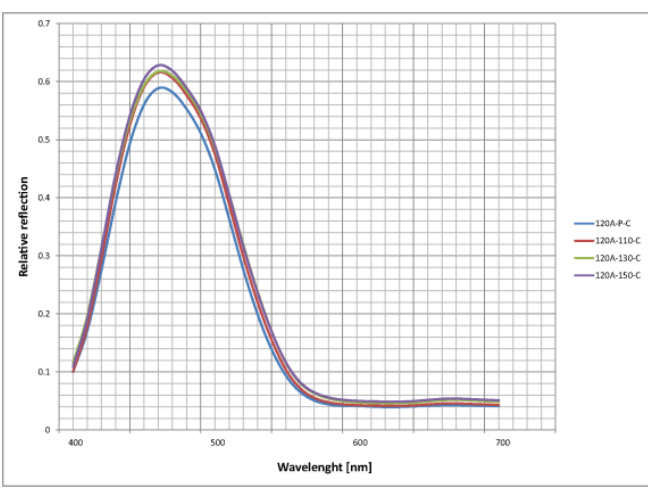

b)

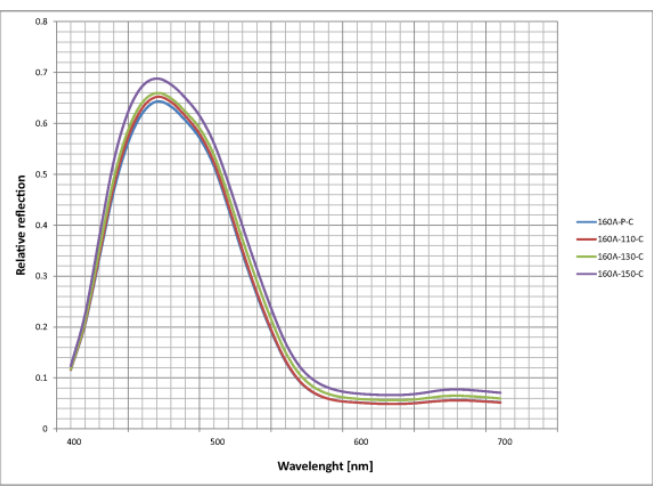

d)

Figure 2: Spectral curves after printing and thermal treatments (material A) of the samples printed using different mesh counts: a) 90 threads/cm, b) 120 threads $/ \mathrm{cm}$, c) 140 threads $/ \mathrm{cm}$, d) 160 threads $/ \mathrm{cm}$. 
The consequence of the heat treatment is greater surface reflectivity, which can be observed in the changes of spectral curves. This can be caused by several reasons, including flattening of the printed ink layer surface under the heating element, degradation of the ink layer, and evaporation of the printed ink layer, which results in decreasing its thickness.

The other samples show the same trend as presented for material A. An increase in heat treatment temperature caused a higher reflectivity of the prints. This is also confirmed by lightness values of $L * a * b *$ colour space in the previous analysis.

\subsection{Macro non-uniformity analysis}

The level of macro non-uniformity is defined by the non-uniformity number (mottling index), which should be 0 in the case of ideal uniformity. In Figure 3, recorded non-uniformity number values for the material $\mathrm{A}$ samples are presented before and after heat treatment, using different temperatures and using different screen mesh counts.

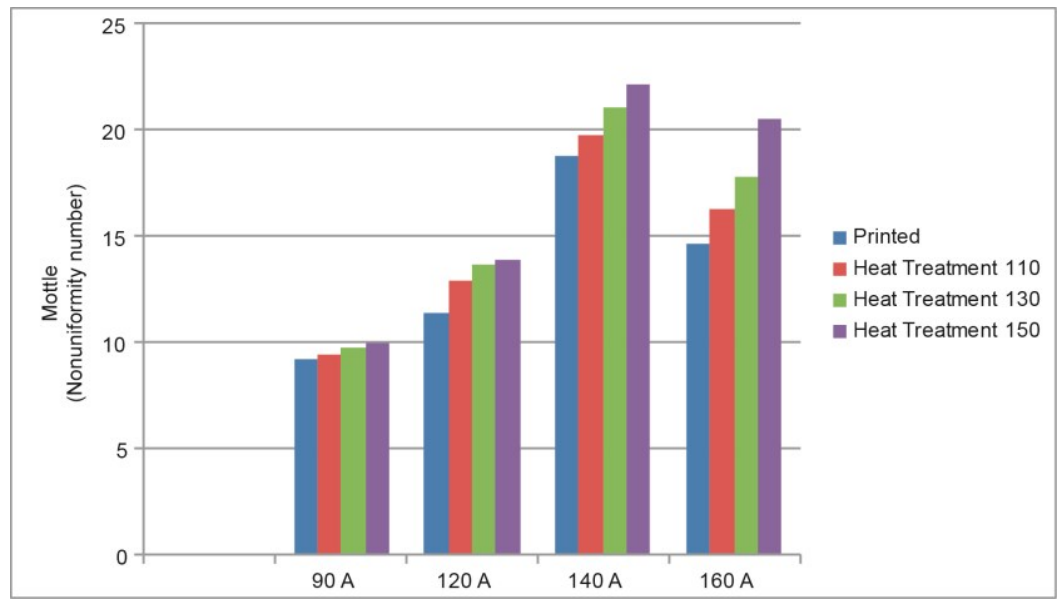

Figure 3: Non-uniformity number values for material A, before and after heat treatment.

The results of the macro non-uniformity analysis indicate that the heat treatment does affect macro non-uniformity. Further, the results show that temperature increase causes higher values of the nonuniformity number of the prints.

The analysis of screen mesh count effect on macro non-uniformity shows that the highest value of macro non-uniformity values was obtained by using screens of 140 threads/cm, followed by screens of 160 threads $/ \mathrm{cm}$. The lowest values of macro non-uniformity were obtained by using screens of 90 threads $/ \mathrm{cm}$. This could be explained by the amount of critical ink deposited, caused by screen mesh count, after which non-uniformity decreases.

In the case of material B, macro non-uniformity number increases with higher thermal load temperatures, as shown in Figure 4. Samples printed using a mesh count of 90 threads/cm show smaller macro non-uniformity values than the other three sample sets do. The highest values of the macro nonuniformity number were recorded for samples printed using a mesh count of 140 threads $/ \mathrm{cm}$, exposed to heat treatment of temperature $150^{\circ} \mathrm{C}$.

The similar macro non-uniformity behavior of samples from the materials A and B could be explained by a more even distribution of ink on the substrate surface, in cases of samples printed using screen mesh of 90 threads/cm.

Macro non-uniformity analysis of material $\mathrm{C}$ shows a decrease of non-uniformity number with the increase of heat treatment temperature, as shown in Figure 5. The highest values of non-uniformity number were noticed in cases of samples printed using screens of 140 threads/cm mesh count. Samples printed using screen mesh counts of 160 threads/cm had the lowest value of the non-uniformity number before heat treatment, but after the treatment, samples printed using screen mesh counts of 90 threads $/ \mathrm{cm}$ had the lowest value of the non-uniformity number. 


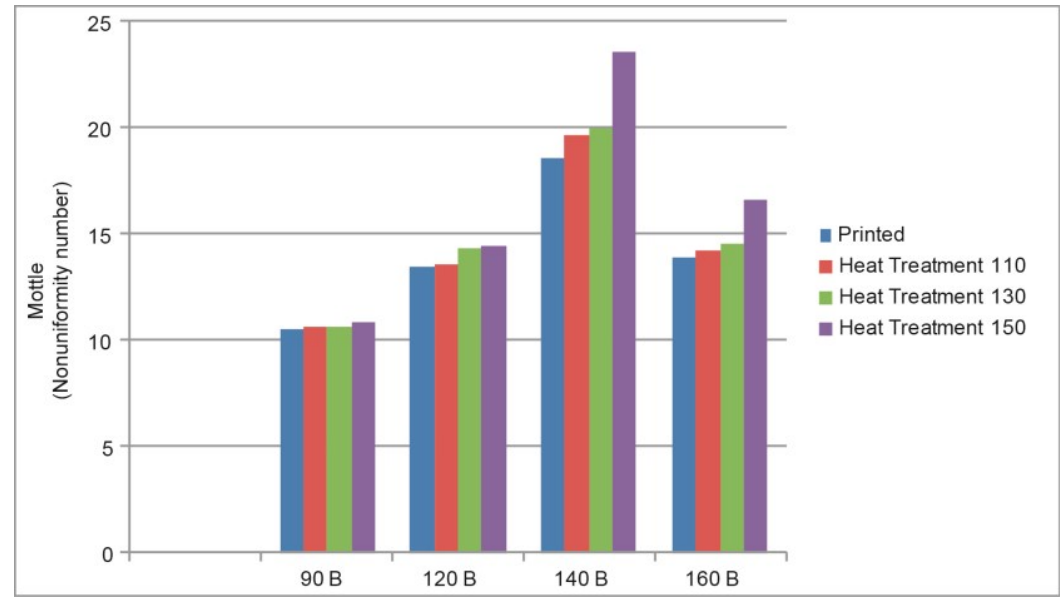

Figure 4: Non-uniformity number values for material B, before and after heat treatment.

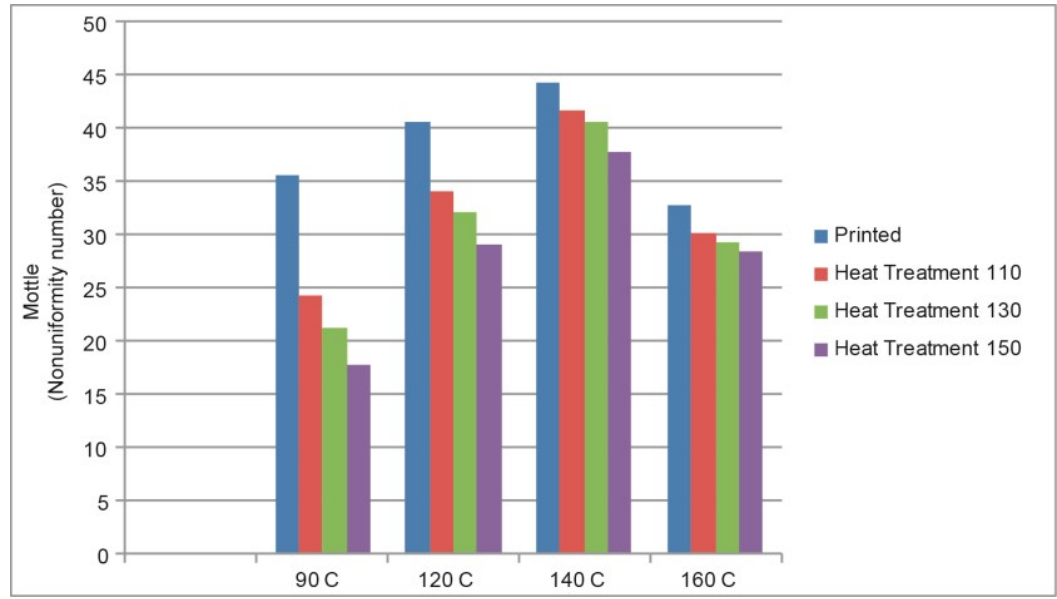

Figure 5: Non-uniformity number values for material C, before and after heat treatment.

In contrast to materials $\mathrm{A}$ and $\mathrm{B}$, material $\mathrm{C}$ has a rougher surface and structure. Applying heat and pressure during heat treatment resulted in decreased roughness of the material and penetration of ink into the fabric structure, which caused a decrease in the non-uniformity number value.

\subsection{SEM analysis}

SEM microscopy images of samples before the printing process, after the printing process using a screen mesh count of 120 threads $/ \mathrm{cm}$, and after they were subjected to heat treatment $\left(150^{\circ} \mathrm{C}\right)$ are shown in Figure 6.

Images that are shown in Figure 6, clearly indicate changes in surface morphology caused firstly by the printing process and later on by the heat treatment. Before printing, it can be noted that the surface of the material is even and the fibers are oriented and undisturbed. Figures $6 \mathrm{~b}, 6 \mathrm{e}$, and $6 \mathrm{~h}$ show deposited ink after the printing process. After heat treatment, some of the ink particles are destroyed (removed), areas with voids and cavities can be seen, as well as areas without ink, and surface flattening under applied heat and pressure is noted.

In order to determine the differences on color prints when printing cotton materials that vary in structure, screen mesh counts or heat treatment temperatures, a mathematical model based on multiple linear regression was designed. 


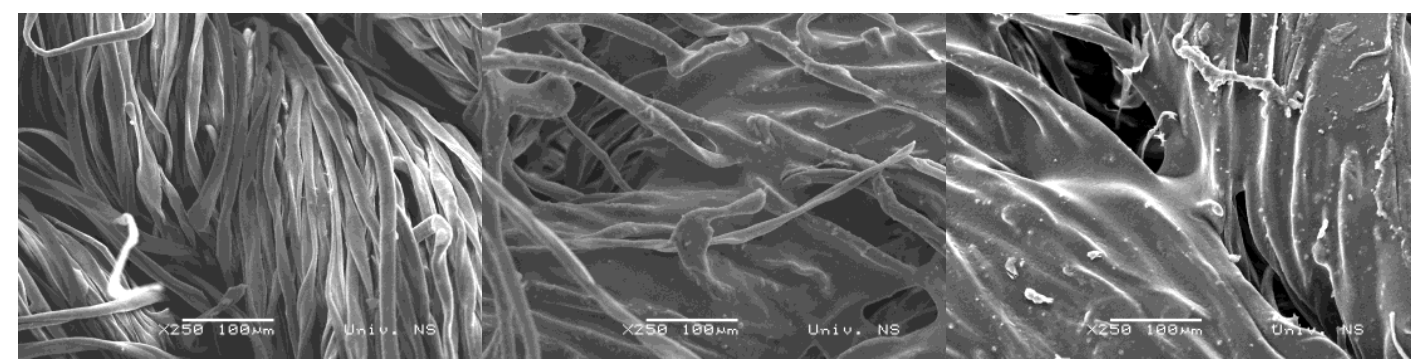

a)

b)

c)

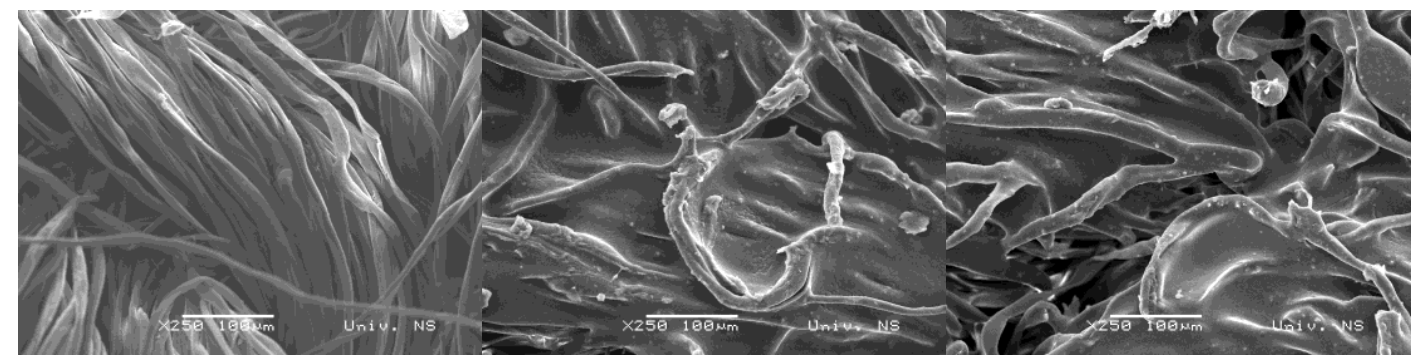

d)

e)

f)

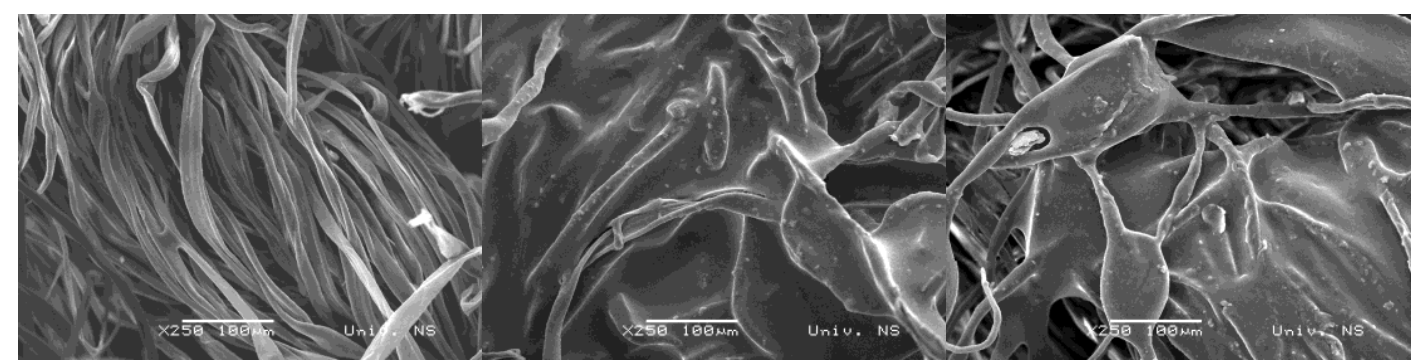

g)

h)

i)

Figure 6: SEM images (250 X): a) material A before printing, b) material A after printing, c) printed material A sample after thermal treatment, d) material B before printing, e) material B after printing, f) printed material B sample after thermal treatment, g) material $\mathrm{C}$ before printing, $\mathrm{h}$ ) material $\mathrm{C}$ after printing, i) printed material $\mathrm{C}$ sample after thermal treatment.

The multiple regression model in the form of an equation expresses the average, regular and quantitative relationship between the dependent variable $\mathrm{Y}$ and $\mathrm{k}$, independent variables $\mathrm{X}_{1}, \mathrm{X}_{2}, \ldots, \mathrm{X}_{\mathrm{k}}$. For the arbitrary dependent variable $Y_{i}$ and selected (fixed) values of the independent variables from the basic set, a multiple regression model is given in the form [28]:

$$
Y_{i}=\beta_{0}+\beta_{1} x_{1 i}+\beta_{2} x_{2 i}+\ldots+\beta_{k} x_{k i}+\varepsilon_{i}
$$

where:

$Y_{i}$ - dependent variable,

$x_{1 i}, x_{2 i}, \ldots, x_{k i}$ - independent variables,

$\beta_{0}, \beta_{1}, \beta_{2}, \ldots, \beta_{k}$ - model parameters,

$\varepsilon_{i}$ - article stochastic or random error

$k$ - number of independent variables

Multiple regression model with two independent variables is given by the formula:

$$
Y_{i}=\beta_{0}+\beta_{1} x_{1 i}+\beta_{2} x_{2 i}+\varepsilon_{i}
$$

The regression coefficients $b_{0}, b_{1}$ and $b_{2}$ representing the theoretical parameter estimation $\beta_{0}, \beta_{1}$ 
and $\beta_{2}$, are determined on the basis of the experimental results. Coefficients of multiple regression of $\Delta \mathrm{E}$ as functions of temperature $\mathrm{Tt}$ and screen mesh count Mc are reported in table 3. Co-dependence of color differences $(\Delta \mathrm{E})$ on the printing screen mesh count Mc and heat treatment temperature $\mathrm{Tt}$ is presented in figure 7.

Table 3: Multiple regression coefficients.

\begin{tabular}{l|l|l}
\hline \multicolumn{4}{|l}{$\Delta \mathrm{E}=-\mathbf{4 , 1 1}+\mathbf{0 , 0 5} \cdot \mathrm{TT}\left({ }^{\circ} \mathbf{C}\right)-\mathbf{0 , 0 1} \cdot \mathbf{M C}($ THREADS/CM) } \\
\hline multiple regression coefficient & $\mathbf{R}^{\mathbf{2}}$ & 0.956 \\
\hline random error regress. & $\mathbf{s}$ & 0.21878 \\
\hline \multirow{4}{*}{$\mathrm{b}_{\mathrm{o}}=-4,111$} & rand.err & 0.295 \\
\cline { 2 - 3 } & $\mathbf{t}$ & -13.945 \\
\cline { 2 - 3 } & $\mathbf{p}$ & 0.00 \\
\hline \multirow{3}{*}{$\mathrm{b}_{1}=0,05041$} & rand.err & 0.002 \\
\cline { 2 - 3 } & $\mathbf{t}$ & 26.294 \\
\cline { 2 - 3 } & $\mathbf{p}$ & 0.00 \\
\hline \multirow{3}{*}{$\mathrm{b}_{2}=0,00529$} & rand.err & 0.001 \\
\cline { 2 - 3 } & $\mathbf{t}$ & -4.373 \\
\cline { 2 - 3 } & $\mathbf{p}$ & 0.00 \\
\hline
\end{tabular}

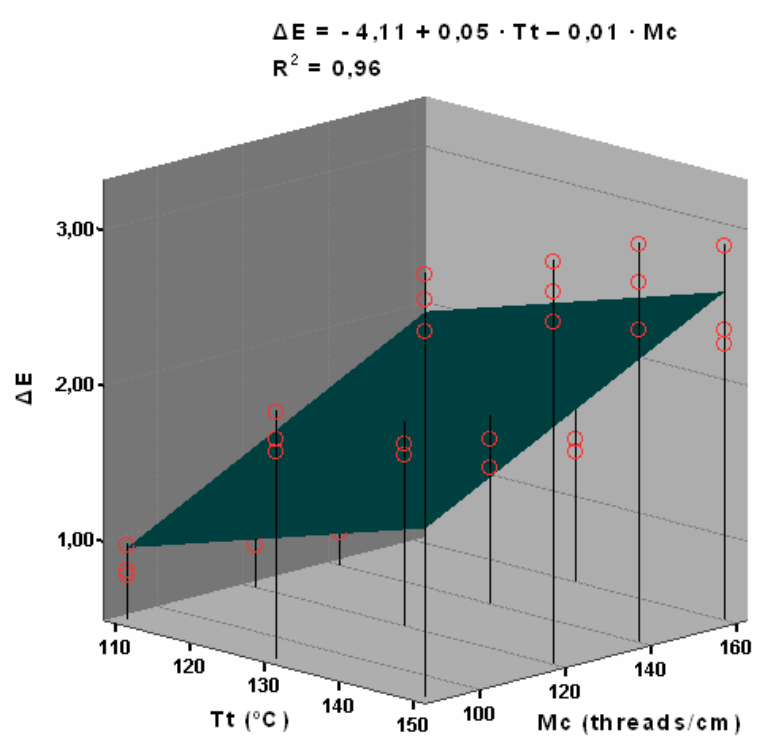

Figure 7: Co-dependence of color differences $\Delta \mathrm{E}$ and printing screen mesh count $\mathrm{Mc}$ and heat treatment temperature Tt.

\section{CONCLUSIONS}

Cotton textile products are exposed to various influences during an exploitation period. One of the influences is heat treatment, which causes both changes of the cotton materials and printed ink. This research examined the influence of different heat treatment temperatures on print quality of three different cotton materials printed with the screen printing process using four different screen mesh counts. Samples were analyzed spectrophotometrically, in respect to their macro non-uniformity characteristics, as well as at a microscopic level using SEM microscopic images. The samples were analyzed before and after heat treatment in order to determine changes caused by the heat treatment.

It was found that the heat treatment of printed textile materials does cause print quality changes. An increase in both color differences $(\Delta \mathrm{E})$ and surface reflectivity was confirmed by the spectrophotometric measurements and the spectral reflection analysis after heat treatment of the samples. The heat treatment caused smaller color differences in the cases of samples printed using higher mesh count screens. This could be due to a smaller amount of ink deposit on the substrate so that a smaller amount of ink was pressed into the material structure during thermal treatment and smaller color changes occurred. Temperature increase also causes greater color and reflectivity changes of the samples, which mean that ink resistance is dependent on the temperature applied. 
The behavior of printed samples depends on material characteristics, fabric weight and thread count. Material A, with the smallest fabric weight, highest thread count and relatively smooth surface compared to materials $\mathrm{B}$ and $\mathrm{C}$, showed the best results when considering print quality parameters after heat treatment.

Macro non-uniformity analysis showed the influence of heat treatment on this print quality parameter, especially at higher temperatures. The fabric weight of the materials showed no significant influence on color differences. However, in the case of macro non-uniformity prints on the materials A and B, an increase of macro non-uniformity with temperature rise was observed, while material C's macro non-uniformity showed a decreasing trend. This should be examined in further studies.

Non-uniform prints, after they were subjected to heat and pressure during the heat treatment process, showed a decrease of macro non-uniformity number, due to lower surface roughness and ink deposit leveling. When higher temperatures are applied, ink migrates into the material structure, causing a decrease of the macro non-uniformity.

Analysis of the samples using SEM microscopic imaging both before and after printing and after the heat treatment, shows higher ink coverage of the printed material surface before the treatment. After hightemperature heat treatments and pressure applications, ink penetrates into the material structure, decreasing ink layer thickness on the material surface.

Using a mathematical model based on the multiple regression, co-dependence of color differences, $\Delta \mathrm{E}$, printing screen mesh count $(\mathrm{Mc})$, and heat treatment $(\mathrm{Tt})$ was determined with a high value of multiple regression coefficient $\mathrm{R}^{2}=0.96$.

It can be concluded that heat treatment is a very influential factor on the print quality of textile products printed using the screen printing technique. Keeping in mind that constant color quality of the product is the goal, it is important to notice that a degree of heat treatment influence can be diminished by selecting adequate textile material characteristics and printing process parameters.

\section{ACKNOWLEDGMENTS}

This research was supported by the Serbian Ministry of Science and Technological Development, Grant No.:35027 "The development of software model for improvement of knowledge and production in graphic arts industry".

\section{BIBLIOGRAPHY}

[1] MILES, L.W.C., Textile Printing, Revised 2 ed., UK, Society of Dyers and Colourists, 2003.

[2] KAŠIKOVIĆ, N., NOVAKOVIĆ, D., KARLOVIĆ, I., et al., "Influence of ink layers on the quality of ink jet printed textile materials", Tekstil ve Konfeksiyon, v. 22, n. 2, pp. 115-124, 2012.

[3] ONAR ÇATAL, D., ÖZGÜNEY, A. T., AKÇAKOCA KUMBASAR, E. P., "The influence of rheological properties of the pretreatment thickeners on ink-jet printing quality", Tekstil ve Konfeksiyon, v. 22, n. 4, pp. 309-316, 2012.

[4] GUPTA, S., "Ink jet printing - A revolutionary ecofriendly technique for textile printing”, Indian journal of fibre \& textile research, v. 26, n. 1-2, pp. 156-161, 2001.

[5] GOBI KANNAN, T., MOU WU, C., BING CHENG, K., et al., "Effect of reinforcement on the mechanical and thermal properties of flax/polypropylene interwoven fabric composites", Journal of Industrial Textiles, v. 42, n. 4, pp. 417-433, 2013.

[6] LOPEZ MANCHADO, M.A., ARROYO, M., BIAGIOTTI, J., et al., "Enhancement of mechanical properties and interfacial adhesion of PP/EPDM/Flax fiber composites using maleic anhydride as a compatibilizer", Journal of Applied Polymers Science, v. 90, n. 8, pp. 2170-2178, 2003.

[7] ARCAYA, P. A., RETEGI, A. A., ARBELAIZ, A., et al., "Mechanical properties of natural fibers/polyamides Composites", Polymer Composition, v. 30, n. 3, pp. 257 - 264, 2008.

[8] KAŠIKOVIĆ, N., NOVAKOVIĆ, D., VLADIĆ, G., et al., "Influence of heat treatment on characteristics of Inkjet print on textile material”, Journal of Graphic Engineering and Design, v. 2, n. 1, pp. 24 - 30, 2011.

[9] STANČIĆ, M., RUŽIČIĆ, B., KAŠIKOVIĆ, N., et al., "Impact of washing treatment on print quality of screen printed knitted fabrics”, Revista Matéria, forthcoming 2016.

[10] STANČIĆ, M., KAŠIKOVIĆ, N., NOVAKOVIĆ, D., et al., "The influence of washing treatment on screen printed textile substrates“, Tekstil ve Konfeksiyon, v. 24, n. 1, pp. 96-104, 2014.

[11] RUŽIČIĆ, B., STANČIĆ, M., KAŠIKOVIĆ, N., et al., "The influence of thermal load on the print 
quality of screen printed knitted fabrics", Advanced technologies, v. 4, n. 1, pp. 78-83, 2015.

[12] MAO, N., RUSSELL, S.J., "The Thermal Insulation Properties of Spacer Fabrics with a Mechanically Integrated Wool Fiber Surface", Textile Research Journal, v. 77, n. 12, pp. 914-922, 2007.

[13] BANKVALL, C., "Heat Transfer in Fibrous Material”, Journal of Testing and Evaluation, v. 1, n. 3, pp. 235-243, 1973.

[14] BOMBERG, M., KLARSFELD, S., "Semi-Empirical Model of Heat Transfer in Dry Mineral Fiber Insulations", Journal of Thermal Insulation, v. 6, n. 1, pp. 157-173, 1983.

[15] HARDERBERG, J. Y., http://www.bookpump.com/bwp/pdf-b/1121350b.pdf, Accessed 21 September 2015.

[16] FEDOROVSKAYA, E. A., BLOMMAERT, F., RIDDER, H., "Perceptual quality of colour figures of natural scenes transformed into CIELUV colour space”, In: IS\&T \& SID's Colour Imaging Conference Proceedings, pp. 37-40, Scottsdale, Arizona, USA, 1993.

[17] DE RIDDER, H., "Naturalness and Figure Quality: Saturation and lightness variation in colour figures", Journal of Imaging Science and Technology, v. 40, n. 6, pp. 487-493, 1996.

[18] FEDOROVSKAYA, E. A., DE RIDDER, H., BLOMMAERT, F., "Chroma variations and perceived quality of colour figures of natural scenes”, Color research and application, v. 22, n. 2, pp. 96 - 110, 1997.

[19] PEDERSEN, M., BONNIER, N., HARDEBERG, J., et al., "Attributes of a new figure quality model for color prints”, In: Proceedings of Color Imaging Conference, pp.: 204 - 209, Albuquerque, New Mexico, USA, 2009.

[20] DALAL, E., RASMUSSEN, D., NAKAYA, F., et al., "Evaluating the overall figure quality of hardcopy output", In: Proceedings of Figure Processing, Figure Quality, Figure Capture, Systems Conference, pp. 169173, Portland, Oregon, USA, 1998.

[21] KIPMAN, Y., "Figure Quality Metrics for Printers and Media”, In: Proceedings of IS\&T's PICS Conference, pp. 183-187, Nashua, New Hampshire, USA, 1998.

[22] DHOPADE, A., "Figure quality assessemnet according to ISO 13660 and ISO 19751", Test Targets 9.0, RIT School of Print Media, Rochester, New York, pp. 43 - 50, 2009.

[23] LINDBERG, S., Perceptual determinants of print quality, Ph.D thesis, Department of Psychology, Stockholm University, Stockholm, Sweden, 2004.

[24] JURIČ, I., KAŠIKOVIĆ, N., STANČIĆ, M., et al., "The influence of heat treatment on print mottle of screen printed textile knitted fabrics“, Applied Thermal Engineering, v. 90, pp. 215-220, 2015.

[25] ENGELDRUM, P.G., “A Theory of Figure Quality: The Figure Quality Circle”, Journal of Imaging Science and Technology, v. 48, n. 5, pp. 446-456, 2004.

[26] MUCK, T., HLADNIK, A., STANIĆ, M., “Analiza tiskovne kakovosti z orodjem ImageJ = Analysis of print quality with ImageJ”, Zbornik Prispevkov, pp. 45 - 49, 2009.

[27] BOZDOĞAN, F., TIYEK, I., ÖZÇELIK KAYSERI, G., “A study on the investigation of the relationship between the inner structure and the physical properties of different lyocell fibers", Tekstil ve Konfeksiyon, v. 20, n. 2, pp. 87-92, 2010.

[28] PALLANT, J., SPSS - A Step by Step Guide to Data Analysis Using SPSS for Windows, Australia, Allan \& Unwin, 2007. Accessed in September 2006. 